\title{
3B yazıcı kullanılarak odun-PLA kompozit filamentinden mobilya bağlantı elemanlarının yazdırılması ve katman kalınlıklarının mekanik özelliklere etkisinin incelenmesi
}

\author{
Nasır Narlığlu*(D)
}

\section{$\ddot{O} \mathbf{z}$}

Bu çalışmada kayın odun-unu ile PLA (Polilaktik asit) polimeri çift vidalı ekstrüderde karıştırıldıktan sonra 3B yazıcı kompozit filamenti elde edilmiştir. Elde edilen kompozit filamentinden mobilya bağlantı elemanları ve farklı katman kalınlıklarında $(0.1,0.2,0.4 \mathrm{~mm})$ mekanik test örnekleri yazdırılmıştır. Mekanik test sonuçlarına göre, yazdırılan kompozitler arasında en yüksek çekme direncini $0.1 \mathrm{~mm}$ katman kalınlığına sahip kompozitlerin (29.26 $\mathrm{MPa})$ sergilediği görülmüştür. Ayrıca, en yüksek eğilme direnci değeri $0.1 \mathrm{~mm}$ katman kalınlığına sahip kompozit örneğinde $50.49 \mathrm{MPa}$ olarak tespit edilmiştir. Katman kalınlığ artışı ile mukavemet arasında genel olarak ters bir orantı olduğu anlaşılmıştır. Ayrıca kompozit örneklerinin enine kesitlerinin, katman kalınlığı artışı sonucu boşluklu olduğu görülmüştür. Bunlara ek olarak kompozit örneklerinin Shore D sertlik değerlerinin birbirine yakın değerler sergiledikleri görülmüştür. Bu çalışmada, odun-PLA kompozit filamentinden mobilya bağlantı elemanlarının başarılı bir şekilde yazdırılabildiği ve katman kalınlığının mekanik özellikler üzerinde önemli derece etkili olduğu sonucuna ulaşılmıştır.

Anahtar kelimeler: 3B yazıcı, Odun-unu, Mobilya bağlantı elemanları, Katman kalınlığı

\section{Printing of furniture fasteners from wood-PLA composite filament using a 3D printer and investigating the effect of layer thicknesses on mechanical properties}

\begin{abstract}
In this study, 3D printer composite filament was obtained after mixing beech woodflour and PLA (Polylactic acid) polymer in a twin-screw extruder. Furniture fasteners and mechanical test samples in different layer thicknesses $(0.1,0.2,0.4 \mathrm{~mm})$ were printed from the obtained composite filament. According to the mechanical test results, it was observed that composites with a layer thickness of $0.1 \mathrm{~mm}(29.26 \mathrm{MPa})$ exhibited the highest tensile strength among the printed composites. In addition, the highest flexural strength value was determined as $50.49 \mathrm{MPa}$ in the composite sample with a layer thickness of $0.1 \mathrm{~mm}$. It has been understood that there is an inverse proportion between the increases of layer thickness with strength in general. Also, it was observed that the cross-sections of the composite samples were porous as a result of the increase the layer thickness. In addition, Shore D hardness values of the composite samples were found close to each other. In this study, it was concluded that furniture fasteners can be successfully printed from the wood-PLA composite filament and the layer thickness has a significant effect on the mechanical properties.
\end{abstract}

Keywords: 3D printer, Wood-flour, Furniture fasteners, Layer thickness

Makale tarihçesi: Geliș:20.11.2021, Kabül:15.12.2021, Yayınlanma:27.12.2021, *e-posta: nasirnarlioglu@ gmail.com, İzmir Kâtip Celebi Üniversitesi, Orman Fakültesi, Orman Endüstri Mühendisliği Bölümü, İzmir/Türkiye,

Atıf: Narlığlu N., (2021), 3B yazıcı kullanılarak odun-PLA kompozit filamentinden mobilya bağlantı elemanlarının yazdırılması ve katman kalınlıklarının mekanik özelliklere etkisinin incelenmesi, Mobilya ve Ahşap Malzeme Araştırmaları Dergisi, 4 (2), 183-192,

DOI: $10.33725 / \operatorname{mamad} .1026248$ 


\section{Giriş}

Eklemeli imalat yöntemi, modern imalat yöntemlerinden biri olup otomotiv, makine, inşaat ve mobilya gibi birçok sektörün hem tasarım aşamalarında hem de imalat aşamalarında yer almaktadır. Son zamanlarda ekstrüzyon, enjeksiyon ve pres kalıplama yöntemlerine alternatif olarak, eklemeli imalat yöntemi kullanılarak polimerlerin ve polimer matrisli kompozitlerin şekillendirilmesi ile ilgili çalışmaların sayısında giderek artış görülmektedir. Lignoselülozik madde ve türevleri (odun-unu, selüloz, lignin vd.) ile çeşitli polimer matrislerin (PLA, Polihidroksibütirat (PHB) vd.) karışımlarından elde edilen kompozit filamentler, eklemeli imalatın yaygın bir türü olan EBM (Eriyik birikim modelleme) yöntemine göre çalışan 3B (üç boyutlu) yazıcılar kullanılarak istenilen boyut ve şekilde ürünlere dönüștürülebilmektedir.

EBM yöntemi basit, güvenilir, ucuz, minimum düzeyde malzeme israfı ve çeşitli malzemelerin kullanılabilirliği nedeniyle en yaygın kullanılan 3B bask1 yöntemidir. EBM yönteminde termoplastik filament, bir besleme dişlisi yardımıyla 1sıtılmış kovan boyunca ittirilerek basınçla sıvılaştırıcı (ekstrüzyon nozülü) kısmına gönderilir. 3B malzemeler, erime sıcaklığına kadar isıtılan ve ekstrüzyon nozülü boyunca ekstrüde edilen filamentin üst üste biriktirilmesiyle katmanlar şeklinde yazdırılır. Sıvılaştırıcı kafa, yazılım tarafından oluşturulan desen yolları boyunca X-Y düzleminde hareket eder ve erimiş filamenti baskı yatağında basılı parçanın temelini oluşturmak için biriktirir. Her katmanın tamamlanmasından sonra, baskı yatağı veya ekstrüzyon nozülü hareket ederek bir sonraki katmanın üretimi için yer açar ve parça tamamlanana kadar her bir katman bir önceki katman üzerine yığılır (Masood ve Song 2004; Ning ve ark., 2015; Tao ve ark., 2017). 3B bask1 işleminde, yazdırılan örneklerin katman kalınlığı, kompozit içerisindeki takviye malzemesinin boyutu ve dolgu yoğunluğu gibi çeşitli parametreler, üretilecek malzemelerin mukavemet özelliklerini etkiler. Bunlar arasında katman kalınlığı 3B yazıcıda kolayca ayarlanabilen ve kontrol edilebilen parametredir (Vaezi ve Chua 2011).

PLA ve ABS (Akrilonitril bütadien stiren) polimerlerinden üretilmiş filamentler EBM yöntemine göre çalışan 3B yazıcılarda yaygın olarak kullanılan hammaddelerdir. Bunlara ek olarak PC (Polikarbonat), PA (Poliamid) ve bunların karışımları da EBM için uygun malzemelerdir (Dudek 2013; Tanikella ve ark., 2017). Saf plastik malzemeler kullanilarak EBM ile üretilen 3B parçaların yüksek maliyet, düşük mukavemet ve kolay bozulma gibi dezavantajları vardır. Bu dezavantajlar EBM'nin işlevselliğinin yanında, yük taşıyan uygulamalarda kullanılacak malzemelerin elde edilmesini ve büyük ölçekli üretimleri kısitlamaktadır (Ning ve ark., 2015). Bu nedenle, EBM için yeni kompozit filamentlerin geliştirilmesi 3B baskı endüstrisinde önemli bir konudur. Ayrıca ahşap malzemelerin eklemeli imalat alanına entegrasyonu, malzeme özelliklerinde iyileşmelerin yanında çevre üzerindeki olumlu etkileri nedeniyle de ilgi çekicidir (Tao ve ark., 2017). Lignoselülozik maddeler ve ana bileşenleri (selüloz, hemiselüloz ve lignin), biyokompozit üretimi için PLA'da dolgu maddesi veya takviye malzemesi olarak kullanılabilen yenilenebilir kaynaklardır. Lignoselülozik maddeler, üretilecek malzemelerin özelliklerini iyileştirebilirler, aynı zamanda maliyetini düşürebilirler veya karbon salınımını azaltabilirler (Bhagia ve ark., 2021).

Mobilyalar, sabit ve demonte olmak üzere iki farklı şekilde üretilebilmektedir. Sabit mobilyaların aksine demonte mobilyalar kullanım yerine ve ihtiyaca göre sökülüp takılabilir olmaları sebebiyle bazı avantajlara sahiptirler. Demonte mobilyaların üretiminde metal ve plastikten üretilmiş bağlantı elemanları yaygın olarak kullanılmaktadır (Trinka 1989; Örs ve Efe 1998). 
$\mathrm{Bu}$ çalışmada, 3B yazıcı kullanılarak odun-PLA kompozit filamentinden mobilya bağlantı elemanlarının yazdırılabilme olanakları ve EBM yönteminde önemli bir parametre olan katman kalınlıklarının kompozitlerin mekanik özelliklerine etkisinin belirlenmesi amaçlanmıştır. $\mathrm{Bu}$ amaçla odun unu ve PLA ekstrüderde karıştırıldıktan sonra odun-PLA kompozit filamenti elde edilmiştir. Elde edilen odun-PLA kompozit filamentinden 3B yazıcı kullanılarak mobilya bağlantı elemanları yazdırılmıştır. Ayrıca farklı katman kalınlıklarında yazdırılmış kompozitlerin mekanik özellikleri birbirleriyle kıyaslanmıştır.

\section{Materyal ve Metot}

\subsection{Materyal}

Bu çalışmada, odun-PLA kompozit filamenti üretimi için dolgu maddesi olarak kayın (Fagus orientalis) odun unu, polimer matris olarak PLA (Polilaktik asit) kullanılmıştır. Kayın odunu Zülkadiroğulları firmasından, PLA polimeri FKUR firmasından temin edilmiştir.

\subsection{Metot}

\subsubsection{Odun-PLA kompozit filamenti üretimi}

Kayın odunu laboratuvar tipi ögütücüde öğ̈̈tüldükten sonra sarsak elekte elenerek tasnif edilmiştir. Tasnif edilen odun-unu $103 \pm 2{ }^{\circ} \mathrm{C}$ 'ye ayarlı fırında tam kuru ağırlığa gelinceye kadar kurutulmuştur. Kompozit filamenti üretimi için 80 mesh üstü $(177-250 \mu \mathrm{m})$ parçacık boyutunda odun-unu kullanılmıştır.

Odun-PLA kompozit filamenti üretimi için ağırlıkça \%30 oranında odun-unu, PLA polimerine ilave edilerek, kalıp açıklığ $1.75 \mathrm{~mm}$ ve L/D oranı 20 olan çift vidalı ekstrüderde karıştırılmıştır. Ekstrüder sıcaklık profili besleme kısmından çıkış kısmına doğru sırasıyla 100-120-140-160-180 ${ }^{\circ} \mathrm{C}$ 'ye, vida hızı ise $50 \mathrm{~d} / \mathrm{d}$ 'ye ayarlanmıştır. Ekstrüde edilmiş $1.75 \mathrm{~mm}$ çapındaki odun-PLA kompozit filamenti, filament sarma makinesi kullanılarak istenilen uzunlukta üretilmiştir.

\subsubsection{Odun-PLA kompozit filamentinin 3B yazıcıda yazdırılması}

Ekstrüde edilmiş $1.75 \mathrm{~mm}$ çapındaki odun-PLA kompozit filamenti, masaüstü 3B yazıcı kullanılarak Çizelge 1'de verilen yazdırma parametreleri kullanılarak yazdırılmıştır.

Çizelge 1. 3B yazıcı yazdırma parametreleri

\begin{tabular}{|c|c|}
\hline Parametre & Değer \\
\hline Katman kalınlığ & $0.1-0.2-0.4 \mathrm{~mm}$ \\
\hline Yazdırma hızı & $50 \mathrm{~mm} / \mathrm{s}$ \\
\hline Baskı tablası sıcaklığ & $55^{\circ} \mathrm{C}$ \\
\hline Nozül sıcaklığ 1 & $190{ }^{\circ} \mathrm{C}$ \\
\hline Yazdırma açısı - tipi & $45^{\circ}-$ kafes \\
\hline Dolgu yoğunluğu & $\% 100$ \\
\hline Nozül çapı & $0.4 \mathrm{~mm}$ \\
\hline
\end{tabular}

Odun-PLA kompozit filamentinin mekanik özelliklerinin belirlenmesi için ASTM standartlarına uygun mekanik test örnekleri yazdırılmıştır (Şekil 1). Kompozit malzemelerin çekme ve eğilme mukavemetlerini belirlemek için sirasılla ASTM D638 ve ASTM D790 standartlarına uygun test örnekleri elde edilmiştir. Mekanik test örnekleri $0.1,0.2$ ve $0.4 \mathrm{~mm}$ katman kalınlıklarında ayrı ayrı yazdırılarak, sırasıyla $1 \mathrm{C}, 2 \mathrm{C}$ ve $4 \mathrm{C}$ kodlarıyla isimlendirilmiştir. 

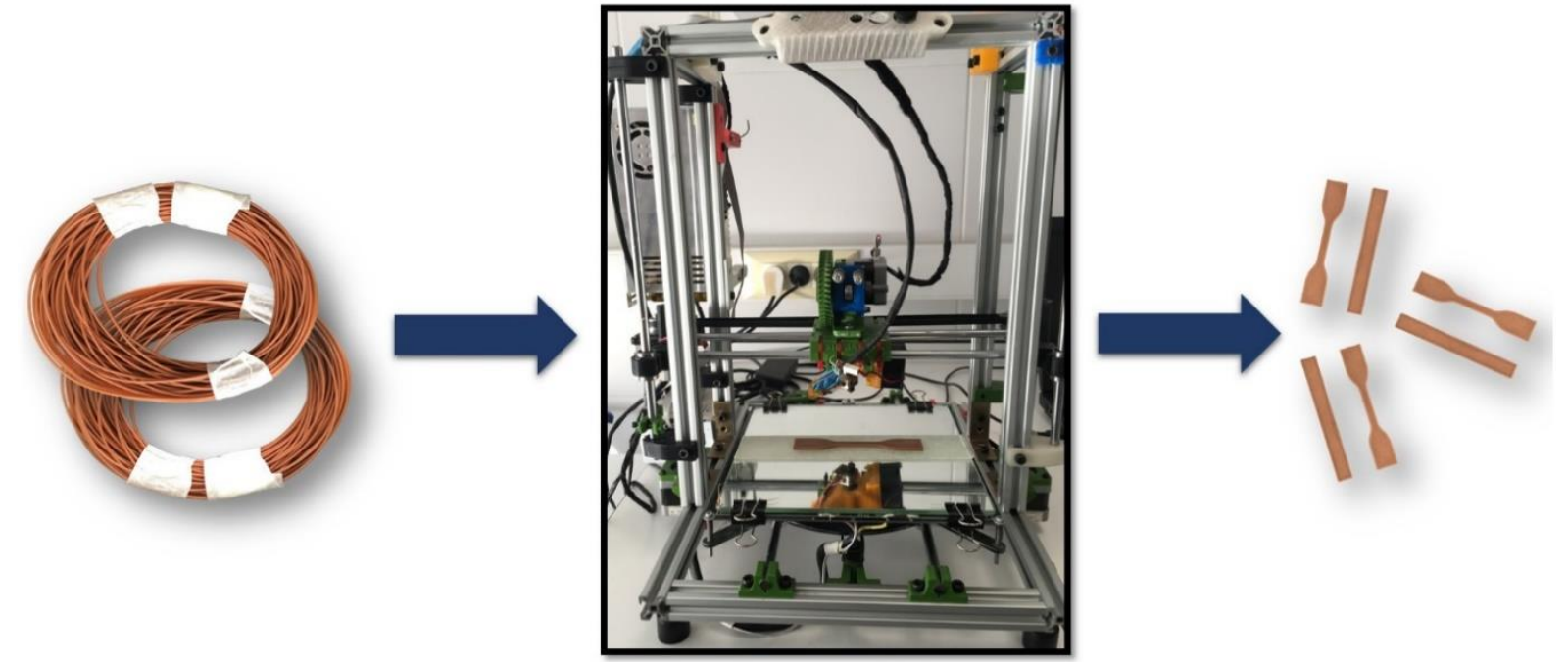

Şekil 1. Ekstrüde edilmiş odun-PLA kompozit filamenti (solda) ve 3B yazıcıda (ortada) basılmış mekanik test örnekleri (sağda)

\subsubsection{Mekanik özelliklerin belirlenmesi}

3B yazıcı kullanılarak ASTM standartlarına göre yazdırılmış test örneklerinin çekme ve eğilme direnci değerlerinin belirlenmesi için $2 \mathrm{kN}$ kapasiteli üniversal mekanik test cihazı kullanılmıştır. Çekme direnci testi ASTM D638, eğilme direnci testi ASTM D790 standardına göre yapılmıştır. Ayrıca, kompozit örneklerinin Shore D sertlik değerlerinin belirlenmesi için ASTM D2240 standardına göre sertlik testi yapılmıştır.

\subsubsection{B yazdırılmış odun-PLA kompozitlerin katmanlarının incelenmesi}

Odun-PLA kompozit filamentinden yazdırılmış kompozit örneklerinin katmanlarının incelenmesi için 200 kat büyütme özelliğine sahip mikroskop kamera (DIGITUS DA-70350) kullanılmıştır.

\subsection{5 İstatistik analizler}

Farklı katman kalınlığında yazdırılmış kompozit örneklerinin mekanik test sonuçlarının karşılaştırılması için SPSS (IBM SPSS Statistics - Version 22) programı kullanılarak varyans analizi (ANOVA) yapılmıştır. Mekanik test sonuçlarından elde edilen sayısal değerler \%95 olasılık düzeyinde F testi tablosu ile karşılaştırılmıştır. F testi sonucuna göre ortalamalar arasındaki farkların anlamlı olması durumunda örnek grupları Tukey testine tabi tutulmuştur. Tukey testi sonucuna göre istatistiksel farklılıklar $(\mathrm{p}<0.05)$ mekanik test grafikleri (Şekil 4-56-7-8) üzerinde küçük harfler ile belirtilmiştir.

\section{Bulgular ve Tartışma}

Odun-PLA kompozit filamentinden mobilya bağlantı elemanlarının 3B yazıcıda yazdırılma olanağının tespiti için köşe bağlantı elemanları yanı sıra kavela ve bisküvi gibi birleştirme elemanları yazdırılmıştır (Şekil 2). Odun-PLA kompozit filamentinden mobilya bağlantı elemanlarının yazdırılması sırasında eriyik haldeki malzemenin baskı tablasına yapışmasında herhangi bir problem görülmemiştir. Ayrıca yazdırılan örneklerin katmanları arasında katman kalkması gibi sorun oluşmamıştır. Bunlara ek olarak yazdırılan kompozit bağlantı elemanlarının ahşap malzeme gibi görünüşe sahip olması, bu bağlantı elemanlarının mobilya sektörü için renk ve desen uyumu açısından tercih edilebilir olacağını göstermiştir. 


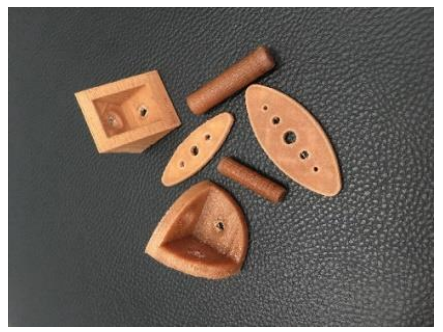

Şekil 2. 3B yazıcıda yazdırılmış mobilya bağlantı elemanları

Şekil 3'te odun-PLA kompozit filamentinden yazdırılmış farklı katman kalınlıklarına sahip kompozitlerin enine kesitlerinin mikroskobik görüntüleri verilmiştir. Kompozitlerin mikroskobik görüntülerinin incelenmesi sonucunda, katman kalınlıklarındaki artış ile katmanlar arasındaki boşlukların arttığı görülmüştür. Ayrıca katman kalınlığının azalması ile katmanların içi içe girip daha iyi kaynaştı̆̆ tespit edilmiştir.
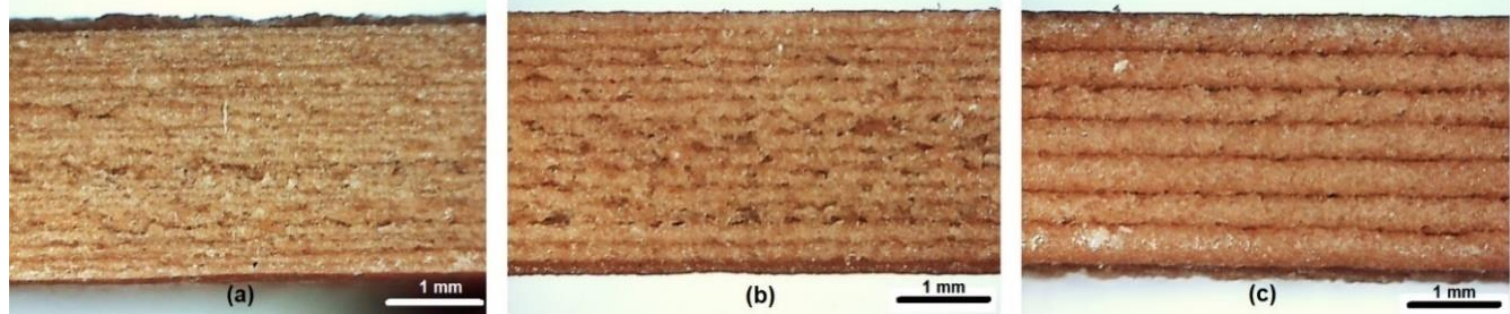

Şekil 3. Farklı katman kalınlıklarında yazdırılmış odun-PLA kompozitlerin enine kesit görünüşleri. a) $0.1 \mathrm{~mm}$, b) $0.2 \mathrm{~mm}$, c) $0.4 \mathrm{~mm}$

Şekil 4'te farklı katman kalınlıklarında yazdırılmış odun-PLA kompozitlerin çekme direnci ve kopmada uzama değerleri verilmiştir. Vaezi ve Chua (2011), 3B yazdırılmış malzemelerin katman kalınlığının belirli sınırlara düşürülmesinin malzemelerin çekme mukavemetini artıracağı ve aynı zamanda katman kalınlıklarındaki azalışla birlikte sabit kalınlıktaki malzemede katman sayısının artmasından dolayı çekme mukavemetinin artacağını bildirmişlerdir. Bazı çalışmalarda 3B yazdırılmış malzemelerin katman kalınlığındaki artışa bağlı olarak malzemelerin çekme dirençlerinin azaldığı bildirilmiştir (Christiyan ve ark., 2016; Ayrilmis ve ark., 2019). Bu çalışmada, 3B yazdırılmış test örneklerinin katman kalınlıklarındaki artışla birlikte çekme direnci değerlerinde azalma görülmüştür. 3B yazdırılmış kompozit örnekleri arasında en yüksek çekme direnci değeri $29.26 \mathrm{MPa}$ ile 0.1 mm katman kalınlığında yazdırılmış 1C kompozit örneğinde tespit edilmiştir. Katman kalınlığının iki kat arttırılmasıyla $(0.2 \mathrm{~mm})$ yazdırılan kompozit örneklerinin ortalama çekme direnci değerinin $23.77 \mathrm{MPa}$ değerini sergilediği görülmüştür. Yazdırılan kompozitler arasında en düşük çekme direnci değeri ise $0.4 \mathrm{~mm}$ katman kalınlığına sahip 4C kompozit örneğinde $20.82 \mathrm{MPa}$ olarak belirlenmiştir. Katman kalınlığı artışı sonucu kompozit örneklerinde görülen çekme direnci değerlerindeki azalışın, katmanlar arasındaki boşluklardan kaynaklanabileceği düşünülmektedir. Bunlara ek olarak kompozit örneklerinin kopmada uzama yüzdelerinin katman kalınlığı artışı ile azaldığı görülmüştür. 0.1 katman kalınlığında yazdırılmış 1C kompozit örneğinin kopmada uzama değeri yaklaşık \%1.9 değerini sergilerken, 0.2 ve 0.4 katman kalınlığında yazdırılmış $2 \mathrm{C}$ ve $4 \mathrm{C}$ kompozit örneklerinin kopmada uzama değerlerinin yaklaşık \%1.4 değeri ile istatistiksel olarak birbirine yakın oldukları görülmüştür. Katman kalınlığı artışı sonucu kopmada uzama değerlerinde görülen azalışın, katmanlar arası zayıf yapışmadan ve azalan katman sayısından kaynaklandığ düşünülmektedir. 


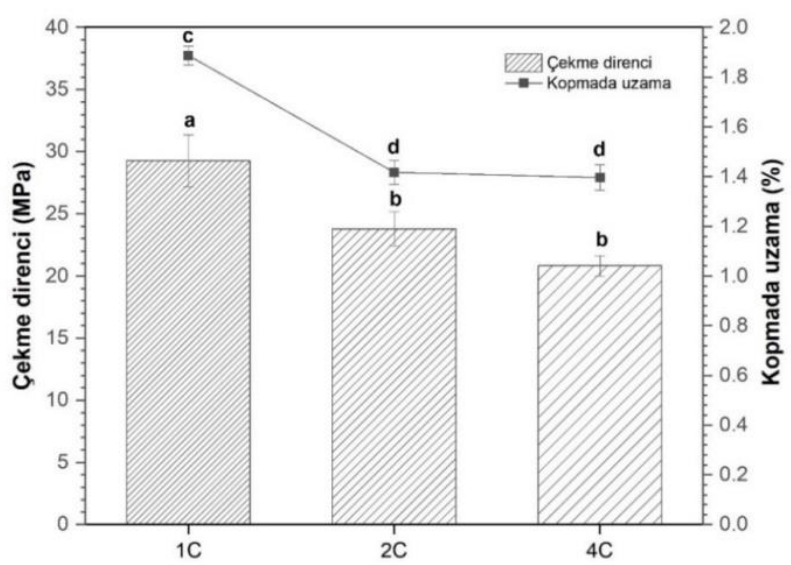

Şekil 4. Farklı katman kalınlığında yazdırılmış odun-PLA kompozitlerin çekme dirençleri (1C: $0.1 \mathrm{~mm}, 2 \mathrm{C}: 0.2 \mathrm{~mm}, 4 \mathrm{C}: 0.4 \mathrm{~mm}$ )

Odun-unu ilaveli PLA kompozit filamenti kullanılarak farklı katman kalınlıklarında yazdırılmış kompozit örneklerinin çekmede elastikiyet modülü değerleri Şekil 5 'te verilmiştir. Şekil 5'te görüldüğü gibi yazdırılan örneklerin katman kalınlığı artışı sonucu, çekmede elastikiyet modülü değerlerinin azaldığı tespit edilmiştir. Kompozit örnekleri arasında en yüksek çekmede elastikiyet modülü değeri $0.1 \mathrm{~mm}$ katman kalınlığında yazdırılmış $1 \mathrm{C}$ kompozit örneğinde $2.6 \mathrm{GPa}$ olarak tespit edilmiştir. Ayrıca $0.2 \mathrm{~mm}$ ve $0.4 \mathrm{~mm}$ katman kalınlığında yazdırılmış $2 \mathrm{C}$ ve $4 \mathrm{C}$ kompozit örneklerinin çekmede elastikiyet modülü değerlerinin sırasıyla 2.46 GPa ve $2.33 \mathrm{GPa}$ değerlerini sergiledikleri görülmüştür. Bunlara ek olarak farklı katman kalınlığında yazdırılmış kompozit örneklerinin çekmede elastikiyet modülü değerlerinin istatistiksel olarak benzer oldukları tespit edilmiştir.

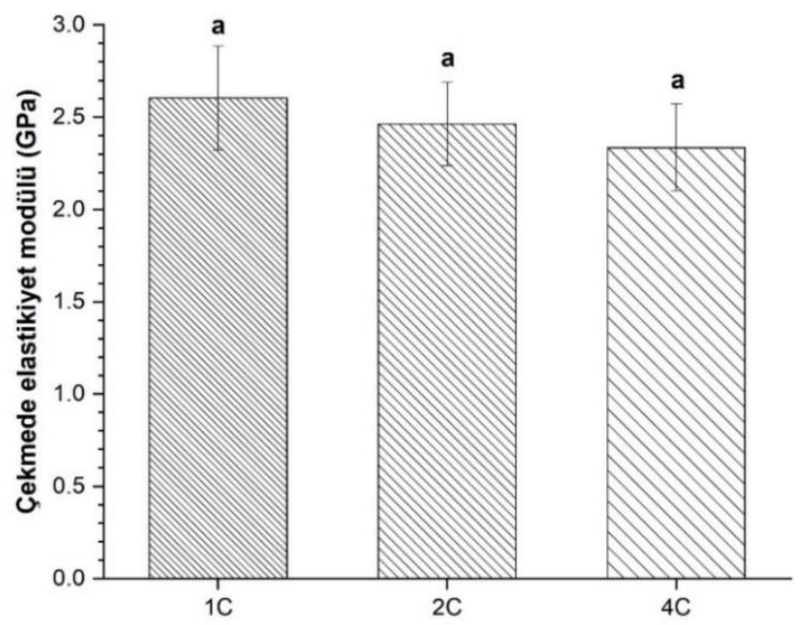

Şekil 5. Farklı katman kalınlığında yazdırılmış odun-PLA kompozitlerin çekmede elastikiyet modülleri (1C: $0.1 \mathrm{~mm}, 2 \mathrm{C}: 0.2 \mathrm{~mm}, 4 \mathrm{C}: 0.4 \mathrm{~mm}$ )

Farklı katman kalınlığında yazdırılmış kompozit örneklerinin eğilme direnci değerleri Şekil 6'da verilmiştir. Kompozit örnekleri arasında en yüksek eğilme direnci değeri, 50.49 MPa değeri ile $0.1 \mathrm{~mm}$ katman kalınlığında yazdırılmış $1 \mathrm{C}$ kompozit örneğinde görülmüştür. Katman kalınlığı artışı ile kompozit örneklerinin eğilme direnci değerlerinde yaklaşık \%30 oranında azalma tespit edilmiştir. Bunlara ek olarak $0.2 \mathrm{~mm}$ ve $0.4 \mathrm{~mm}$ katman kalınlığında yazdırılmış $2 \mathrm{C}$ ve $4 \mathrm{C}$ kompozit örneklerinin eğilme direnci değerlerinin sırasıyla $38.14 \mathrm{MPa}$ 
ve $35.38 \mathrm{MPa}$ değerlerini sergiledikleri görülmüştür. 3B yazıcılardaki katman kalınlığı parametresinin, malzemelerin eğilme dirençleri üzerinde etkisinin olduğu ve katman kalınlığının azaltılması sonucunda eğilme direnci değerinin arttığı bildirilmiştir (Vaezi ve Chua 2011). Kompozitlerin katman kalınlıklarının eğilme mukavemeti üzerindeki etkisi, çekme mukavemeti ve çekmede elastikiyet modülünde olduğu gibi katman kalınlığındaki artış ile birlikte mukavemet değerlerinde azalış şeklinde kendini göstermiştir. Katman kalınlığ1 artışı ile eğilme direnci değerlerinde görülen azalış sebebinin, katmanlar arası boşluklu yapıdan ve katmanların birbirine zayıf tutunmalarından kaynaklandığı düşünülmektedir.

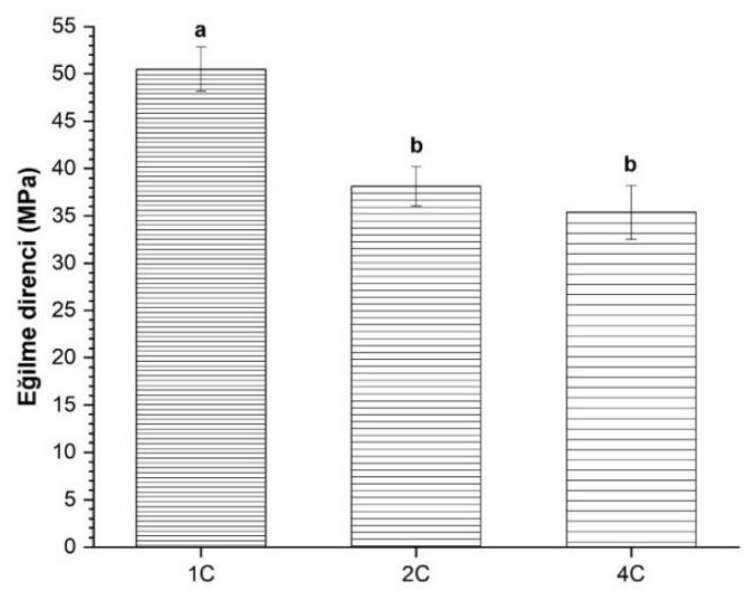

Şekil 6. Farklı katman kalınlığında yazdırılmış odun-PLA kompozitlerin eğilme dirençleri (1C: $0.1 \mathrm{~mm}, 2 \mathrm{C}: 0.2 \mathrm{~mm}, 4 \mathrm{C}: 0.4 \mathrm{~mm}$ )

Şekil 7'de farklı katman kalınlığında yazdırılmış kompozit örneklerinin eğilmede elastikiyet modülleri verilmiştir. Şekil 7'de görüldüğü gibi katman kalınlığı artışıyla birlikte kompozit örneklerinin eğilmede elastikiyet modülü değerleri azalmıştır. En yüksek eğilmede elastikiyet modülü değeri $0.1 \mathrm{~mm}$ katman kalınlığında yazdırılmış 1C kompozit örneğinde $1.78 \mathrm{GPa}$ olarak, en düşük eğilmede elastikiyet modülü değeri ise $0.4 \mathrm{~mm}$ katman kalınlığında yazdırılmış 4C kompozit örneğinde $1.39 \mathrm{GPa}$ olarak tespit edilmiştir. Benzer bir çalışmada $3 \mathrm{~B}$ yazdırılmış kompozit örneklerinin katman kalınlığındaki artışa bağlı olarak eğilmede elastikiyet modülü değerlerinin azaldığı bildirilmiştir (Ayrilmis ve ark., 2019).

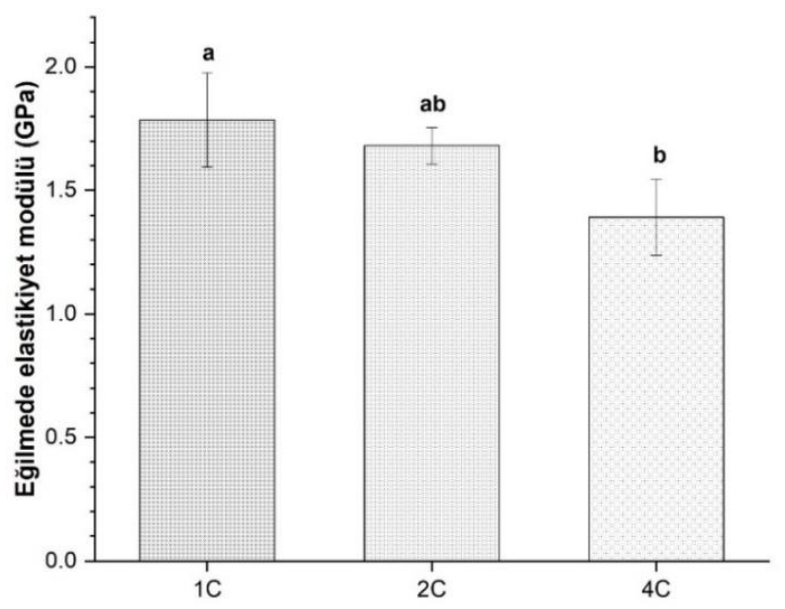

Şekil 7. Farklı katman kalınlığında yazdırılmış odun-PLA kompozitlerin eğilmede elastikiyet modülleri (1C: $0.1 \mathrm{~mm}, 2 \mathrm{C}: 0.2 \mathrm{~mm}, 4 \mathrm{C}: 0.4 \mathrm{~mm}$ ) 
Farklı katman kalınlığında yazdırılmış odun-PLA kompozitlerin Shore D sertlik değerleri Şekil 8'de verilmiştir. Şekil 8'de görüldüğü gibi kompozit örneklerinin sertliklerinin birbirlerine benzer değerler sergiledikleri tespit edilmiştir. Bu çalışmada, $0.1,0.2$ ve $0.4 \mathrm{~mm}$ katman kalınlığında yazdırılmış $1 \mathrm{C}, 2 \mathrm{C}$ ve $4 \mathrm{C}$ kompozit örneklerine ait ortalama Shore D sertlik değerleri sırasıyla 73, 73 ve 72 olarak ölçülmüştür. Bir çalışmada, $\% 10-15-20$ oranında mısır sap1 tozu eklenmiş PLA kompozitlerin Shore D sertlik değerlerinin 70-80 arasında olduğu bildirilmiştir. (Jiang ve ark., 2021). Diğer bir çalışmada ise \%5-10-15-20 oranında karaçam odun-unu eklenmiş PLA kompozit filamentlerinden yazdırılmış örneklerden \%5 odun-unu ilaveli kompozit örneğinin 72.2 Shore D sertlik değeri sergilediği, diğer kompozit örneklerinin sertlik değerlerinin ise birbirine yakın oldukları bildirilmiştir (Narlığlu ve ark., 2021). Bu çalışmada 3B yazdırılmış kompozit örneklerinin Shore D sertliklerinin genel olarak katman kalınlıkları değişiminden fazla etkilenmedikleri görülmüştür. 3B yazdırılmış kompozit örneklerinin Shore D sertliklerinin birbirine yakın değerler sergilemesinin nedeninin, çekme ve eğilme direnci testlerinde görülen katman ayrılması gibi oluşumların Shore D sertlik testinde görülmemesinden kaynaklandığı tahmin edilmektedir.

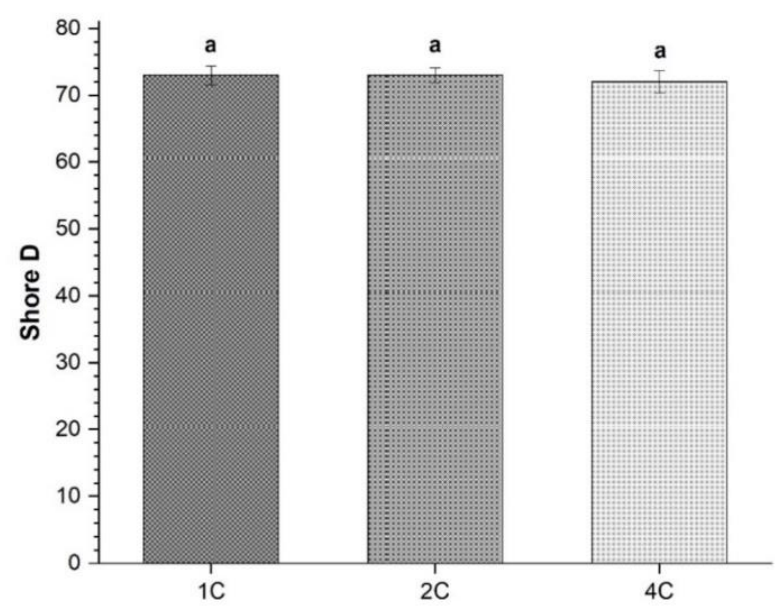

Şekil 8. Farklı katman kalınlığında yazdırılmış odun-PLA kompozitlerin Shore D sertlikleri (1C: $0.1 \mathrm{~mm}, 2 \mathrm{C}: 0.2 \mathrm{~mm}, 4 \mathrm{C}: 0.4 \mathrm{~mm}$ )

\section{Sonuçlar ve Öneriler}

3B yazıcı kullanılarak odun-PLA kompozit filamentinden mobilya bağlantı elemanlarının yazdırılması ve katman kalınlıklarının mekanik özelliklere etkisinin incelenmesi isimli bu çalışma sonunda aşağıdaki sonuçlar elde edilmiştir.

- Kayın odun-unu ile PLA polimeri çift vidalı ekstrüderde karıştırıldıktan sonra 3B yazıcıda yazdırılabilecek çapta odun-PLA kompozit filamenti elde edilmiştir. Elde edilen odun-PLA kompozit filamentinden mobilya bağlantı elemanları ve mekanik test örnekleri sorunsuz bir şekilde yazdırılmıştır.

- Kompozitlerin katman kalınlığındaki artışa bağlı olarak mukavemet değerlerinde azalış görülmüştür.

- Katman kalınlıklarındaki değişimin sertlik direncine etkisinin çekme ve eğilme direncindeki gibi etkili olmadığı tespit edilmiştir.

- Değişik odun türlerinin farklı katılım oranlarında PLA polimeri ile karıştırılması sonucunda elde edilecek filamentlerin 3B yazıcıda yazdırılması ve yazdırılmış 
kompozit malzemelerin özelliklerinin incelenmesi bu konuya ilgi duyan araştırmacılara tavsiye edilmektedir.

- Ayrıca diğer yazdırma parametrelerinin (yazdırma hızı, sıcaklık, yazdırma açısı vb.) kompozit malzemelerin fiziksel ve mekanik özelliklerine etkisinin araştırılması bu çalışma alanını daha da kapsamlı hale getirecektir.

\section{Kaynaklar}

ASTM D2240, (2015), Standard test method for rubber property-durometer hardness, ASTM International, West Conshohocken, PA.

ASTM D638, (2014), Standard test method for tensile properties of plastics, ASTM International, West Conshohocken, PA.

ASTM D790, (2017), Standard test methods for flexural properties of unreinforced and reinforced plastics and electrical insulating materials, ASTM International, West Conshohocken, PA.

Ayrilmis, N., Kariz, M., Kwon, J. H., Kuzman, M. K., (2019), Effect of printing layer thickness on water absorption and mechanical properties of 3D-printed wood/PLA composite materials, The International Journal of Advanced Manufacturing Technology, 102(5), 2195-2200. DOI: 10.1007/s00170-019-03299-9

Bhagia, S., Bornani, K., Agarwal, R., Satlewal, A., Durkovič, J., Lagaňa, R., Ragauskas, A. J., (2021), Critical review of FDM 3D printing of PLA biocomposites filled with biomass resources, characterization, biodegradability, upcycling and opportunities for biorefineries, Applied Materials Today, 24, 101078. DOI: 10.1016/j.apmt.2021.101078

Christiyan, K. J., Chandrasekhar, U., Venkateswarlu, K., (2016), A study on the influence of process parameters on the mechanical properties of 3D printed ABS composite. In IOP Conference Series: Materials Science and Engineering, 114(1), 012109. DOI: 10.1088/1757-899X/114/1/012109

Dudek, P., (2013), FDM 3D printing technology in manufacturing composite elements, Archives of Metallurgy and Materials, 58, 1415-1418. DOI: 10.2478/amm-2013-0186

Jiang, J., Gu, H., Li, B., Zhang, J., (2021), Preparation and properties of straw/PLA wood plastic composites for 3D printing, Earth and Environmental Science, 692(3), 032004. DOI: $10.1088 / 1755-1315 / 692 / 3 / 032004$

Masood, S. H., Song, W. Q., (2004), Development of new metal/polymer materials for rapid tooling using fused deposition modelling. Materials \& Design, 25, 587-594. DOI: 10.1016/j.matdes.2004.02.009

Narlığlu, N., Salan, T., Alma, M. H., (2021), Properties of 3D-Printed wood sawdustreinforced PLA composites. BioResources, 16(3). DOI: 10.15376/biores.16.3.54675480

Ning, F., Cong, W., Qiu, J., Wei, J., Wang, S., (2015), Additive manufacturing of carbon fiber reinforced thermoplastic composites using fused deposition modeling, Composite Part B Engineering, 80, 369-378. DOI: 0.1016/j.compositesb.2015.06.013

Örs, Y., Efe, H., (1998), Mobilya (çerçeve konstrüksiyon) tasarımında bağlantı elemanlarının mekanik davranış özellikleri. Turkish Journal of Agriculture and Forestry, 22(1), 21-27. 
Tanikella, N. G., Wittbrodt, B., Pearce, J. M., (2017), Tensile strength of commercial polymer materials for fused filament fabrication 3D printing, Additive Manufacturing, 15, 40-47. DOI: 10.1016/j.addma.2017.03.005

Tao, Y., Wang, H., Li, Z., Li, P., Shi, S. Q., (2017), Development and application of wood flour-filled polylactic acid composite filament for 3D printing, Materials, 10(4), 339. DOI: $10.3390 / \mathrm{ma} 10040339$

Trinka, M., (1989) Ready-to-assemble furniture; marketing and material use trends, Forest Products Journal, 40(3), 35-39.

Vaezi, M., Chua, C. K., (2011), Effects of layer thickness and binder saturation level parameters on 3D printing process. The International Journal of Advanced Manufacturing Technology, 53(1), 275-284. DOI: 10.1007/s00170-010-2821-1 